\title{
Arthroplasty in veterans: Analysis of cartilage, bone, serum, and synovial fluid reveals differences and similarities in osteoarthritis with and without comorbid diabetes
}

\author{
Trevor W. Oren, MD; ${ }^{1-2}$ Sergiu Botolin, MD, PhD; ${ }^{1}$ Allison Williams, ND, PhD, RN; ${ }^{1-2}$ Allan Bucknell, MD; ${ }^{1-2}$ \\ Karen B. King, $\mathbf{P h D}^{1-2 *}$ \\ ${ }^{1}$ Department of Orthopaedics, University of Colorado School of Medicine, Aurora, CO; ${ }^{2}$ Eastern Colorado Health \\ Care System, Department of Veterans Affairs, Denver, CO
}

\begin{abstract}
Osteoarthritis patients with diabetes who receive total knee arthroplasty are more vulnerable to complications, including aseptic loosening and need for revision surgery. To elucidate mechanisms related to arthroplasty failure in diabetes, we examined serum and synovial fluid markers as well as collagen crosslinks in bone and cartilage of 20 patients (10 with diabetes, 10 controls without) undergoing this procedure. Hemoglobin A1c, body mass index, bone alkaline phosphatase, leptin, osteocalcin, and pyridinium were analyzed along with tissue content of the crosslinks hydroxylysylpyridinoline, lysylpyridinoline, and pentosidine. Pentosidine levels in tissue specimens from diabetic subjects were higher than in control subjects. Osteocalcin levels negatively correlated with hydroxylysylpyridinoline levels in cartilage. Osteocalcin levels also negatively correlated with pentosidine levels in cartilage, but only in subjects with diabetes. This study suggests potential metabolic mechanisms for arthroplasty failure in patients with diabetes.
\end{abstract}

Key words: arthroplasty, bone, cartilage, collagen, diabetes, leptin, osteoarthritis, osteocalcin, pentosidine, veterans.

\section{INTRODUCTION}

In adults, total knee arthroplasty (TKA) is the second most common surgical procedure performed by orthopedic surgeons. Dramatic improvement in both function and pain relief have made this procedure desirable for many patients with end-stage osteoarthritis (OA). With the population of adults 65 and older expected to double by 2050, rates for TKA in this country are expected to rise significantly [1]. Long-term follow-up studies have documented the durability of this intervention, with expected implant survival rates of greater than 15 years [2]. Still, 3 percent failure rates are observed each year as a result of noninfectious etiologies such as component loosening [1]. Revision TKA is associated with lower functional outcome and higher complication rates than primary intervention. Significant healthcare costs are associated with this procedure; the average charge in the United States for revision TKA is \$73,696 [1]. Not only

\footnotetext{
Abbreviations: $\mathrm{AGE}=$ advanced glycation end product, $\mathrm{BAP}=$ bone alkaline phosphatase, BMI = body mass index, DM = diabetes mellitus, ELISA = enzyme-linked immunosorbent assay, HbA1c = hemoglobin A1c, HFBA = heptafluorobutyric acid, HP = hydroxylysylpyridinoline, HPLC = high-performance liquid chromatography, LP = lysylpyridinoline, $\mathrm{OA}=$ osteoarthritis, OCN $=$ osteocalcin, $\mathrm{PYD}=$ pyridinium, $\mathrm{RAGE}=$ receptor for AGE, TKA = total knee arthroplasty, VA = Department of Veterans Affairs.

*Address all correspondence to Karen B. King, PhD; Department of Orthopaedics, University of Colorado School of Medicine, 12800 E. 19th Ave, Room 2103, Aurora, CO 80045; 303-724-1596; fax: 303-724-0394.

Email: Karen.King@UCDenver.edu

DOI:10.1682/JRRD.2010.09.0186
} 
is the revision procedure associated with higher costs than a primary TKA, but it is also associated with longer lengths of hospitalization, up to 6.6 days on average. This equates to projected hospital costs exceeding $\$ 2$ billion by 2030 [1].

Diabetes mellitus (DM) is one of numerous factors that have been implicated in higher rates for revision arthroplasty [3-6]. The revision rate among those with diabetes is up to 9 times higher in some studies [3,5]. The issue of revision arthroplasty is amplified within the Department of Veterans Affairs (VA) population, where the incidence of DM (20.0\%) is higher relative to that of the U.S. general population (5.5\%) [7]. Reasons behind DM-related arthroplasty failures include superficial and deep surgical infections [3,8], higher joint stiffness and aseptic loosening rates $[2,5,9]$, and dramatic effects on the musculoskeletal system [10], including alteration of bone mineral density [11].

DM effects on bone mineral density have been attributed to decreased mechanical qualities of the bone matrix rather than bone mass [12-13]. Cadaveric studies have shown that increased concentration of nonenzymatic glycation products (also called advanced glycation end products [AGEs]) within the collagen network of bone correlate with many bone mechanical properties, including ultimate strength, yield strength, and fracture toughness [14]. Nonenzymatic modifications of collagen are also significantly increased in bone from DM animal models $[13,15]$. Furthermore, the products of these nonenzymatic glycation events, AGEs, increase stiffness and brittleness of articular cartilage [16]. Articular cartilage is therefore more prone to mechanical damage with $\mathrm{DM}$, a problem compounded by the increasing age and body mass index (BMI) of the U.S. and veteran populations. Additionally, one study of rats with DM reports a decrease in the immature forms of a different class of collagen crosslinks that mature to the forms called hydroxylysylpyridinoline (HP) and lysylpyridinoline (LP) [13]. HP and LP are created by posttranslational modification resulting in inter- and intramolecular collagen crosslinks [17]. These crosslinks are beneficial in that they stabilize the collagen matrix and, thus, increase tissue mechanical strength [18-19]. Thus, DM could potentially increase harmful crosslinks while decreasing beneficial crosslinks.

Bone remodeling is a continuous process mediated by a constant interaction between osteoblasts and osteoclasts and directly affects bone mechanics. This process is associated with the release of several biochemical markers ("biomarkers") in the blood stream. Osteocalcin (OCN) has been demonstrated to be an indicator of bone formation [20-22], and previous studies have shown decreased baseline levels among DM patients [23]. Further, one study analyzing the differences in these levels among patients undergoing TKA showed statistically higher OCN levels at 12 months postoperative in those patients with potentially unstable fixation of the tibial component [24]. Levels of another biomarker, leptin, correlate to obesity. Several studies have demonstrated the effects of leptin on articular cartilage [25-28]. One study in particular found that leptin had a detrimental effect on chondrocyte proliferation and induced production of interleukin-1 beta and metalloproteinases that mediate the destructive process on articular cartilage in OA [27]. Furthermore, leptin has been identified as a potent inhibitor of bone formation via a pathway in the central nervous system [29].

This study explored the hypothesis that diabetes status is related to bone and joint homeostasis in order to better understand the molecular mechanisms affecting orthopedic surgical outcomes among those with comorbid diabetes. Specifically, this study's goal was to measure and analyze circulating and local biomarkers as well as tissue collagen crosslinks in the following two groups: (1) veterans diagnosed with diabetes and receiving total knee joint replacement (i.e., TKA), and (2) a reference group of veterans not diagnosed with diabetes but also receiving TKA. The ultimate goal is to use new knowledge of the molecular effects of DM status to improve arthroplasty outcomes for this population.

\section{METHODS}

\section{Overview}

To accomplish our objectives, we used a crosssectional, prospective design to recruit 20 patients scheduled for TKA at the Denver VA Medical Center to donate a preoperative blood sample and the tissue wastes from their planned surgeries. The blood and tissues were processed in the research laboratory to measure diabetes-, obesity-, and OA-relevant molecules as described subsequently. The differences between groups and the relationships between variables were analyzed.

\section{Subjects}

The inclusion criteria were male surgical patient, aged 45 to 80, from the Denver VA Medical Center, and with radiographic and clinical evidence of end-stage OA. 
Exclusion criteria were rheumatoid arthritis, osteoporosis on bisphosphonate therapy, Paget disease or other metabolic bone diseases, renal impairment (serum creatinine $>1.3$ ), drug therapies including antiretrovirals and anticonvulsants known to influence bone metabolism, and receipt of steroids (either intraarticular or oral) within the last 12 months. Twenty subjects were enrolled: ten patients with a diagnosis of diabetes and ten control patients without this diagnosis. In this report, the two study groups are designated as "DM" or "non-DM," respectively. Subjects were enrolled consecutively without regard to race/ethnicity. Demographic and clinical data (hemoglobin A1c [HbA1c], albumin, creatinine, electrolytes, and liver function tests) were collected from chart review.

\section{Sample Collection}

Venous blood samples were collected from subjects at the time of their preoperative appointment (typically 2 weeks before surgery). After centrifugation, the serum was frozen in aliquots and stored at $-80^{\circ} \mathrm{C}$ for later analysis. All subjects underwent hybrid TKA with press-fit femoral and patellar components and a cemented tibial component.

When the knee joint was opened during the surgery, all synovial fluid was collected without dilution and stored at $-80^{\circ} \mathrm{C}$ for later analysis. From one of the subjects, no synovial fluid was available ("a dry joint”). The data of this subject, therefore, were omitted from statistical analyses using synovial fluid data.

Standard femoral and tibial cuts were made in preparation for arthroplasty. These tissues were placed in labeled sterile bags, passed out of the sterile field, and then held at $4^{\circ} \mathrm{C}$ for sample dissection (described below) within 1 hour of surgery.

\section{Analysis of Fluid Samples}

Biomarkers for obesity (common to type $2 \mathrm{DM}$ ) and bone formation/resorption (bone remodeling is necessary for implant fixation following arthroplasty) were analyzed in serum and synovial fluid. Concentrations of leptin, bone alkaline phosphatase (BAP), OCN, and pyridinium (PYD) were measured in samples that had been subjected to only one freeze-thaw cycle. The specific enzyme-linked immunosorbent assays (ELISAs) used were commercially available kits (Quidel Corporation; San Diego, California, catalog numbers: TE1016, 8012, 8002, and 8019, respectively). Manufacturer's instructions were followed. Sam- ples were run neat; no sample had concentration values outside the standard curve for any of the four biomarkers. Concentrations were determined from a standard curve of calibrators that were provided in each kit and plotted as recommended (e.g., linear, quadratic). All samples were measured in duplicate. For the PYD assay, samples were filtered before analysis with a $30 \mathrm{kD}$ molecular weight cutoff filter as provided in the kit.

\section{Analysis of Joint Tissue Samples}

Tissue samples (5 $\mathrm{mm}$ in diameter) were cored from the tibial cuts. One core from the central one-third of the lateral tibial plateau was used for this study. Bone and cartilage were separated and then hydrolyzed in $6 \mathrm{~N} \mathrm{HCl}$, $18 \mathrm{~h}$, at $108^{\circ} \mathrm{C}$. Diluted and filtered samples were analyzed for levels of the collagen crosslinks pentosidine, HP, and LP by using high-performance liquid chromatography (HPLC) following the collagen crosslink protocol of Bank et al. [30]. Filtered samples were diluted 1:5 in 10 percent acetonitrile and 0.05 percent heptafluorobutyric acid (HFBA) and then loaded to a Gemini-NX C-18 column (Phenomenex; Torrance, California) fitted to a programmable gradient HPLC system (model 126, Beckman-Coulter; Fullerton, California). The autosampler, gradient pump, and data analysis were controlled by 32 Karat Workstation software v. 5.0 (Beckman Coulter, Inc; Brea, California). Samples were separated with $20 \mathrm{~min}$ of solvent containing 24 percent methanol and 0.15 percent HFBA, 10 min of solvent containing 40 percent methanol and 0.05 percent HFBA, and 10 min of solvent containing 75 percent acetonitrile and 0.1 percent HFBA. The column was equilibrated in 24 percent methanol and 0.15 percent HFBA for at least 12 min between sample runs. Collagen crosslink peaks were measured with a programmable fluorescence detector (model FP1520, JASCO; Easton, Maryland). The detection wavelengths for HP and LP were $295 \mathrm{~nm}$ excitation and $400 \mathrm{~nm}$ emission (0-26 min) and those for pentosidine were $328 \mathrm{~nm}$ excitation and $378 \mathrm{~nm}$ emission (after $26 \mathrm{~min}$ ). Crosslink concentration was calculated from a standard curve of five dilutions of a calibrator containing all three crosslinks. Purified calibrators HP and LP were purchased from Quidel Corporation, while purified pentosidine was purchased from Dr. L. Sayre, Case Western Reserve University (Cleveland, Ohio).

All crosslink concentrations were normalized to collagen concentration, which was estimated from hydroxyproline concentration as measured by HPLC. To measure hydroxyproline, an aliquot of the above diluted sample 
was further diluted 1:50 and then derivatized with 9fluorenylmethyl chloroformate and separated on the same system as described, following the amino acid protocol of Bank et al. [31]. This protocol used the following three solutions: (1) $20 \mathrm{mM}$ citric acid and $5 \mathrm{mM}$ tetramethylammonium chloride, $\mathrm{pH}$ 2.85; (2) $20 \mathrm{mM}$ sodium acetate and $5 \mathrm{mM}$ tetramethylammonium chloride, $\mathrm{pH} 4.5$; and (3) 100 percent acetonitrile. The gradient elution profile was as follows: from 0 to $11.5 \mathrm{~min}$ a gradient of 75 percent (1)/25 percent (3) to 60 percent (1)/40 percent (3), at 13 min switch directly to 64 percent (2)/36 percent (3), from 13.1 to $18 \mathrm{~min}$ a gradient of 64 percent (2)/36 percent (3) to 62 percent (2)/38 percent (3), from 18 to $25 \mathrm{~min}$ a gradient of 62 percent (2)/38 percent (3) to 30 percent (2)/70 percent (3), from 25 to $30 \mathrm{~min}$ a gradient of 30 percent (2)/70 percent (3) to 25 percent (2)/75 percent (3), at $32 \mathrm{~min}$ a switch directly to 75 percent (1)/25 percent (3) and then end at $45 \mathrm{~min}$. The column was equilibrated in 75 percent (1)/25 percent (3) for at least 12 min between sample runs. Amino acid peaks were measured with the same fluorescence detector using $254 \mathrm{~nm}$ excitation and $630 \mathrm{~nm}$ emission for the entire protocol. Hydroxyproline concentration was calculated from a standard curve of five dilutions of an amino acid standard made from collagen hydrolysate (Sigma-Aldrich \#H1007; St. Louis, Missouri). The conversion of hydroxyproline to collagen concentration is 285 mol hydroxyproline per mol collagen and is based on the constant concentration of hydroxyproline in fibrillar collagen [32].

For interpreting the data, note that HP (measured in cartilage and bone by HPLC) and PYD (measured in serum and synovial fluid by ELISA) are similar molecules but represent different biological entities. HP is the actual collagen crosslink that was a part of the collagen matrix at the time the tissue was obtained. PYD, on the other hand, is the crosslink that has been released from the collagen matrix and enters the circulation during tissue degradation before blood draw. Thus, PYD in the circulation represents collagen breakdown.

\section{Data Analyses}

Data were analyzed statistically with SigmaPlot/Systat, v. 11.2 (Systat Software, Inc; San Jose, California). Data were tested for normality with the Shapiro-Wilk normality test as well as for equal variance. Statistical analyses to detect differences between the non-DM and DM groups were performed with the unpaired, two-tailed test (normal data) or the Mann-Whitney rank sum test (non-normal data). The strengths of associations between variables were determined with the Pearson product moment correlation test. For significant correlations between variables, multiple linear regression analysis was used to test associations after adjusting for potential confounders. Statistical significance for all tests was declared a priori at $p<0.05$.

\section{RESULTS}

\section{Comparison of Variables Between Control Group (non-DM) and Diabetes Group (DM)}

All subjects were veterans. The two groups were of similar age, race/ethnicity, and BMI, and all were male (Table 1). All subjects were being treated for late-stage knee OA with total joint arthroplasty. The difference in mean preoperative HbA1c was statistically significant $(p=$ 0.003). None of the non-DM subjects had ever been diagnosed with diabetes. Nine subjects of the DM group were diagnosed with type $2 \mathrm{DM}$ and one subject with type 1 .

To test whether differences existed between groups for levels of AGEs, we measured the biomarker for AGEs (pentosidine) in bone and in cartilage (Figure 1). The bone from the DM group had 32 percent higher levels of pentosidine than the bone from the non-DM group $(p=0.05)$. While the DM group appeared to have 21 percent higher levels of cartilage pentosidine than the nonDM group, this difference was not statistically significant $(p=0.07)$. The power of the performed test $(0.316)$ was below the desired power of 0.800 , suggesting a lower likelihood of detecting a difference in bone if one actually exists.

We also tested the two other collagen crosslinks (HP and LP). No differences were found between groups for HP level in either bone or cartilage (data not shown). The LP crosslink was not detected in two cartilage samples (previous studies have demonstrated that LP levels are normally very low for cartilage [33]); however, for the samples that did yield detectable levels of LP and also for bone, no differences were found between groups (data not shown).

\section{Correlations Between Biomarkers and Joint Tissue Collagen Crosslinks}

We next analyzed data to determine whether biomarkers and other variables associated with DM (HbA1c), obesity (BMI, leptin), and bone synthesis/turnover (BAP, OCN, and PYD) were correlated to joint tissue collagen 
Table 1.

Demographics and clinical characteristics of veterans scheduled for total knee arthroplasty. Data presented as \% $(n)$ unless otherwise noted.

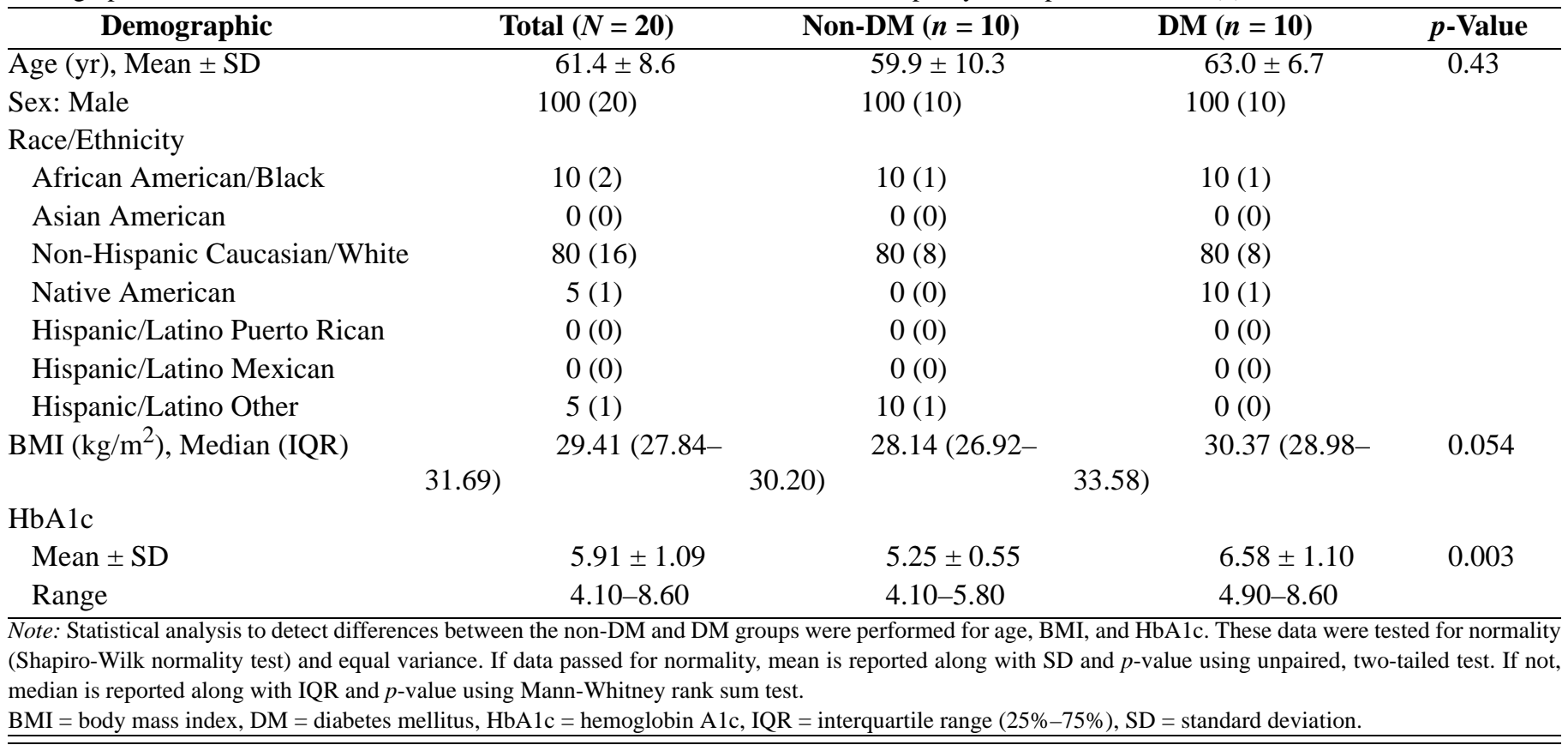

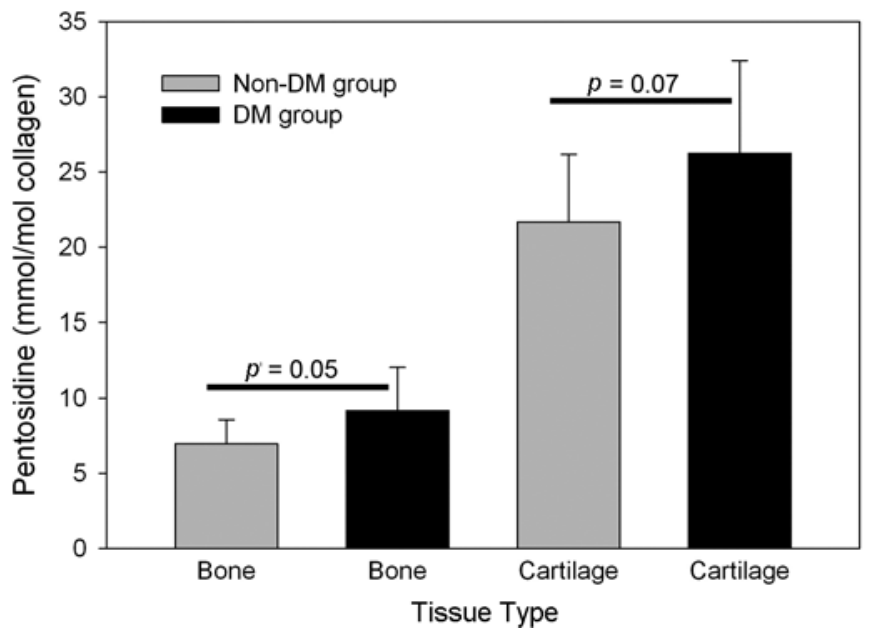

Figure 1.

Pentosidine content of bone and cartilage tissue obtained from total knee arthroplasty. Black bars represent diabetes mellitus (DM) group, and light gray bars represent non-DM group.

crosslink molecules (pentosidine, HP, and LP). The levels of variables were obtained from medical records (HbA1c and BMI), measured by ELISA in blood serum and synovial fluid (leptin, OCN, and PYD) or measured by HPLC (pentosidine, HP, and LP). The strengths of association between measures (Pearson product moment) are displayed in Table 2.

Not surprisingly, the two markers for obesity (BMI and leptin) were strongly correlated to each other regardless of whether leptin was measured in the serum or the synovial fluid. Note, however, that a less strong and nonsignificant correlation was found when the non-DM group was examined separately (Table 2 ).

Next, correlations between serum and synovial fluid were tested for each of the four biomarkers measured by ELISA in both fluids (Table 2 and Figure 2). A very strong correlation $(r>0.900)$ was found between serum and synovial fluid leptin (Table 2 and Figure 2(a)). This correlation was significant regardless of whether the groups were examined together or separately. For OCN, a strong correlation between the two fluids was found only in the DM group (Table 2 and Figure 2(b)). No correlations were found between the two fluids for either BAP or PYD (Figure 2(c) and (d)), indicating that these two metabolites are processed differently and that these biomarkers may be appropriate for systemic analysis (i.e., in serum) but not necessarily for local articular joint analysis (i.e., in synovial fluid). One explanation may be that these metabolites pass from the synovial fluid to the greater circulation quite quickly. Another would be the influence of tissue source; for example, a greater contribution from a nonlocal bone 
source in the serum sample compared with the local synovium source in the synovial fluid sample [34].

Table 2.

Pearson product correlations between measures. These tests were used to identify relationships between variables without designating which is explanatory and which is response variable.

\begin{tabular}{lllll}
\hline \multicolumn{1}{c}{ Factor 1 } & \multicolumn{1}{c}{ Factor 2 } & \multicolumn{1}{c}{ All Subjects } & Non-DM Only & DM Only \\
\hline BMI & Serum Leptin & $\boldsymbol{r}=\mathbf{0 . 7 5 0} ; p<0.001$ & $r=0.580 ; p=0.08$ & $\boldsymbol{r}=\mathbf{0 . 8 4 1 ;} p=0.002$ \\
BMI & Synovial Fluid Leptin & $\boldsymbol{r}=\mathbf{0 . 7 9 8} ; p<0.001$ & $r=0.495 ; p=0.14$ & $\boldsymbol{r}=\mathbf{0 . 9 1 9} ; p<0.001$ \\
Serum Leptin & Synovial Fluid Leptin & $\boldsymbol{r}=\mathbf{0 . 9 2 4} ; p<0.001$ & $\boldsymbol{r}=\mathbf{0 . 9 6 0} ; p<0.001$ & $\boldsymbol{r}=\mathbf{0 . 9 1 2} ; p<0.001$ \\
Serum OCN & Synovial Fluid OCN & $r=0.425 ; p=0.07$ & $r=0.080 ; p=0.82$ & $\boldsymbol{r}=\mathbf{0 . 7 3 5} ; p=0.02$ \\
Bone Pentosidine & Cartilage Pentosidine & $\boldsymbol{r}=\mathbf{0 . 7 1 8} ; p<0.001$ & $r=0.575 ; p=0.08$ & $\boldsymbol{r}=\mathbf{0 . 6 9 5} ; p=0.03$ \\
Serum OCN & Cartilage HP & $\boldsymbol{r}=-\mathbf{0 . 4 7 4} ; p=0.03$ & $r=-0.089 ; p=0.81$ & $r=-0.579 ; p=0.08$ \\
Synovial Fluid OCN & Cartilage HP & $\boldsymbol{r}=-\mathbf{0 . 5 6 6} ; p=0.01$ & $\boldsymbol{r}=-\mathbf{0 . 8 3 5} ; p=0.003$ & $r=-0.502 ; p=0.17$ \\
Serum BAP & Cartilage HP & $r=-0.398 ; p=0.08$ & $r=0.472 ; p=0.17$ & $\boldsymbol{r}=-\mathbf{0 . 6 4 3} ; p=0.04$ \\
Synovial Fluid OCN & Cartilage Pentosidine & $r=-0.309 ; p=0.20$ & $r=0.112 ; p=0.76$ & $\boldsymbol{r}=-\mathbf{0 . 8 3 5} ; p=0.005$ \\
Synovial Fluid OCN & Bone Pentosidine & $r=0.0303 ; p=0.90$ & $\boldsymbol{r}=\mathbf{0 . 6 5 5} ; p=0.04$ & $r=-0.464 ; p=0.23$ \\
Serum Leptin & Bone HP & $\boldsymbol{r}=\mathbf{0 . 5 3 8} ; p=0.01$ & $\boldsymbol{r}=\mathbf{0 . 7 0 0 ;} p=0.02$ & $r=0.466 ; p=0.17$ \\
Synovial Fluid Leptin & Bone HP & $\boldsymbol{r}=\mathbf{0 . 5 6 8} ; p=0.01$ & $r=0.599 ; p=0.07$ & $r=0.503 ; p=0.17$ \\
\hline
\end{tabular}

Note: Pearson product correlation coefficients $(r)$ that were found significant $(p \leq 0.05)$ are displayed in bold font.

BMI and HbA1c values were taken from patient medical records. Leptin, OCN, BAP, and PYD were measured by enzyme-linked immunosorbent assay, and pentosidine and HP were measured by high-performance liquid chromatography.

$\mathrm{BAP}=$ bone alkaline phosphatase, $\mathrm{BMI}=$ body mass index, $\mathrm{DM}=$ diabetes mellitus, $\mathrm{HbA1c}=$ hemoglobin $\mathrm{A} 1 \mathrm{c}, \mathrm{HP}=$ hydroxylysylpyridinium, $\mathrm{OCN}=$ osteocalcin, PYD = pyridinium.

Regarding the joint tissue collagen crosslinks, cartilage pentosidine and bone pentosidine were strongly correlated to each other (Table 2). Correlations were significant for all subjects together and for the DM group considered alone but did not reach significance for the non-DM group considered alone.

The cartilage HP crosslink was negatively correlated to both serum and synovial fluid OCN, with some variation in strength of correlation depending on whether groups were tested together or separately (Table 2 and Figure 3(a) and (b)).

In some tests, the correlations for the non-DM group were opposite those of the DM group. A moderately strong and negative correlation $(r>-0.600)$ was found between serum BAP and cartilage HP for the DM group, but not for the non-DM group, which appeared to have a (nonsignificant) positive correlation (Table 2 and Figure 4(a)). The correlation between synovial fluid OCN and cartilage pentosidine was strong and negative for the DM group but was not significant for the non-DM group (Table 2 and Figure 4(b)). Conversely, the correlation between synovial fluid OCN and bone pentosidine was strong and positive for the non-DM group but was not significant for the DM group (Table 2 and Figure 4(c)).

DM and obesity variables correlated with some biomarkers and crosslinks depending on DM status. Both serum and synovial fluid leptin were correlated to bone HP, but not significant for the DM group tested separately (Table 2 and Figure 5(a) and (b)). Also of note, but not reaching significance, was a positive association between HbA1c and serum PYD for the DM group ( $r=0.594, p=$ 0.07 ), but no suggestion of a relationship for the non-DM group ( $r=0.350, p=0.32$ ). An inverse relationship between serum OCN and $\mathrm{HbA1c}$ was suggested by data in the DM group only, but this was not significant $(r=-0.466, p=$ 0.17 ). The non-DM group suggested an opposite effect ( $r=$ $0.507, p=0.13$ ). No such relationship was found between synovial fluid OCN and HbA1c (data not shown).

\section{Models for Relationships Between Synovial Fluid Biomakers and Joint Tissue Collagen Crosslinks in Osteoarthritis}

Because local (synovial fluid) levels of some analytes were correlated with pentosidine and/or with HP, we next sought to determine whether these were independent factors by using multiple regression analysis. Since age and BMI are risk factors for knee OA, these factors were included in the models.

As shown in Table 3, synovial fluid OCN was an independent factor associated with collagen crosslinks $(p<$ 0.05). Model 1 revealed that synovial fluid OCN of the indexed knee was an independent factor for cartilage 
(a)
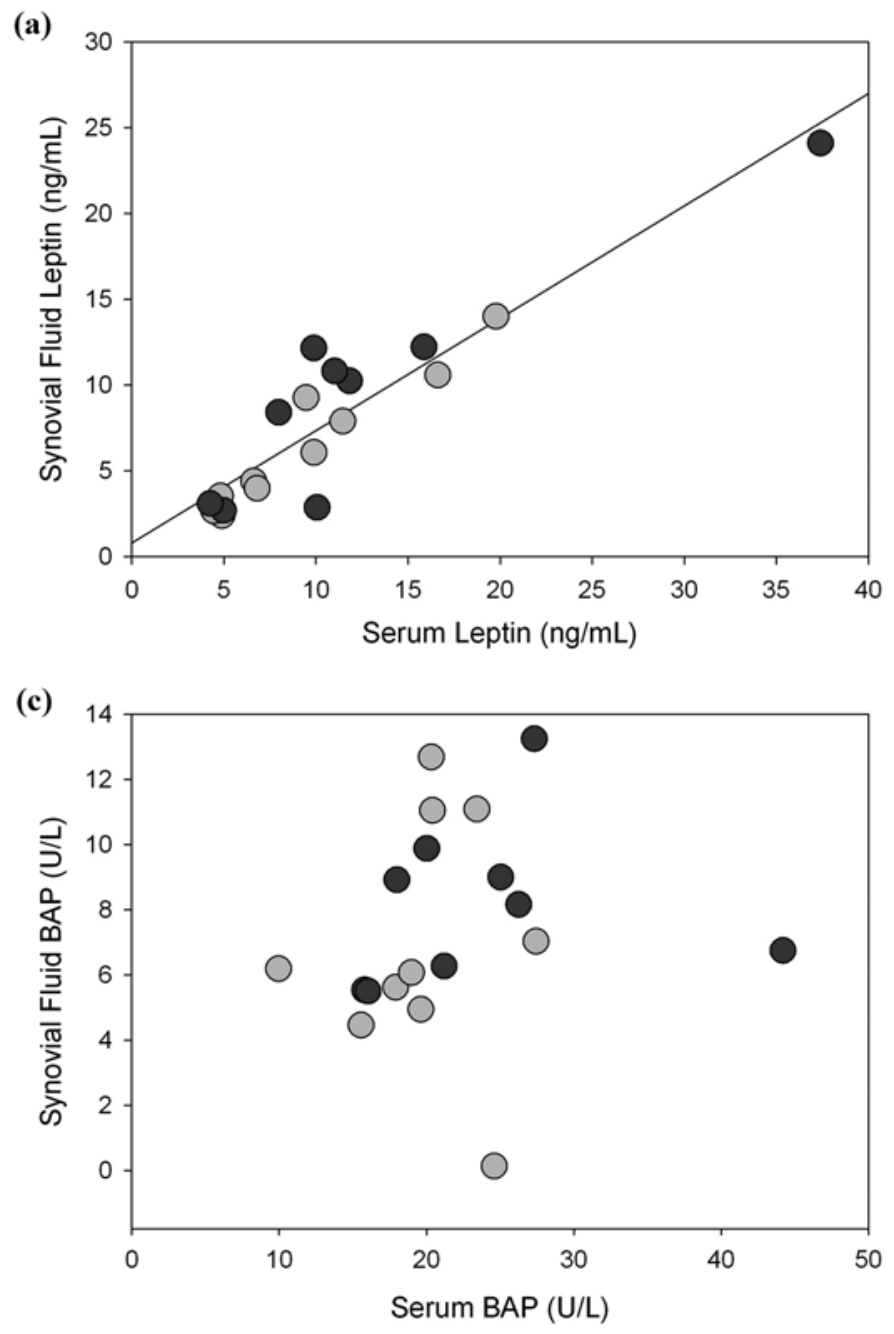

(b)

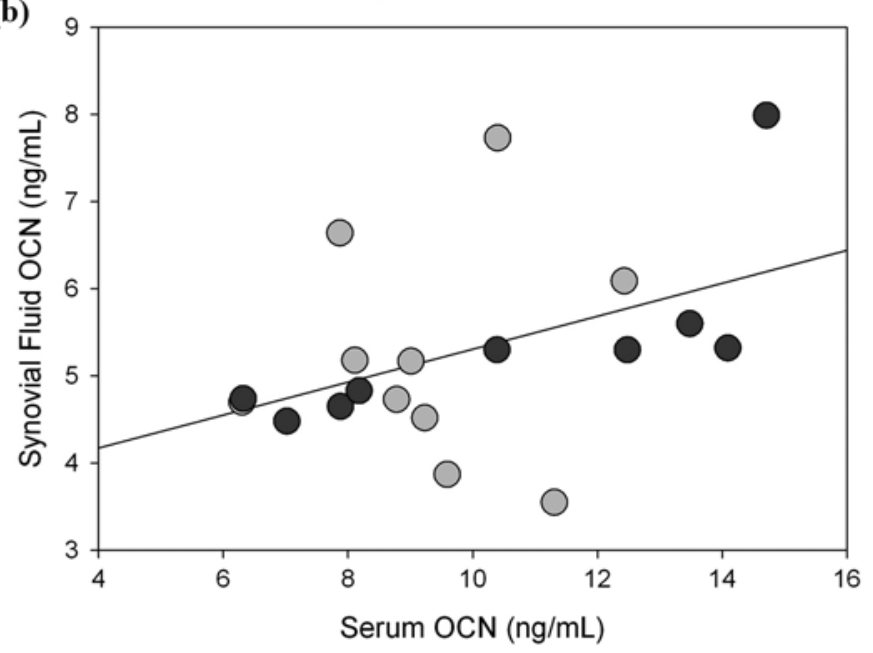

(d)

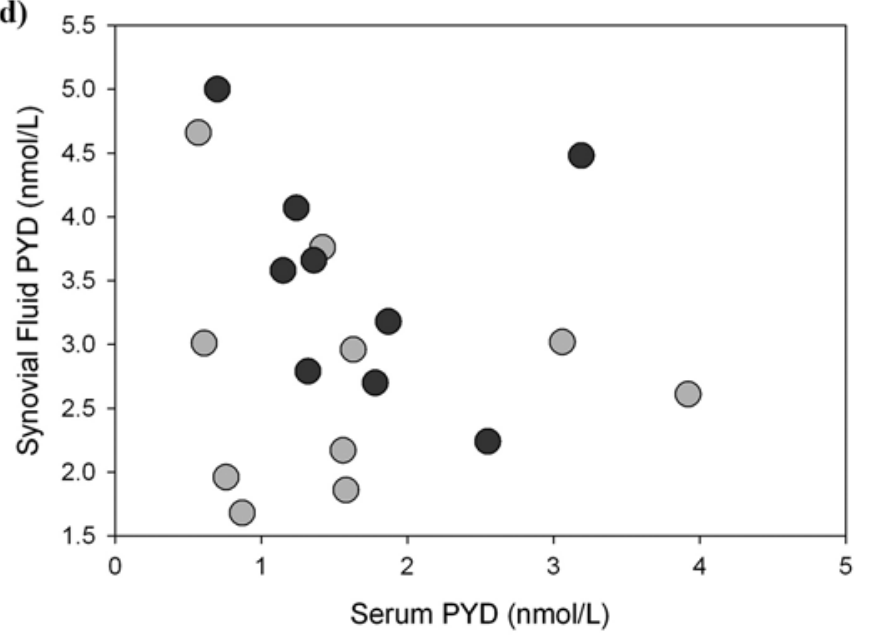

Figure 2.

Correlation, if any, between serum and synovial fluid levels of four biomarkers. (a) Leptin levels in serum were correlated to those in synovial fluid. (b) Osteocalcin (OCN) levels in serum were correlated to those in synovial fluid. (c) Bone alkaline phosphatase (BAP) levels in serum were not correlated to those in synovial fluid. (d) Pyridinium (PYD) levels in serum were not correlated to those in synovial fluid. Black filled circles represent diabetes mellitus (DM) group, and light gray filled circles represent non-DM group. Regression line is indicated with black line.

pentosidine in OA subjects diagnosed with DM. Model 2 revealed that synovial fluid OCN of the indexed knee was an independent factor for cartilage HP regardless of DM status.

The correlation between synovial fluid leptin and bone HP was also tested by regression analysis. However, because of the correlation between leptin and BMI, BMI was not included in the leptin model. Also, because of skewness, data were log transformed before analysis. Model 3 (Table 3) revealed that synovial fluid leptin of the indexed knee was an independent factor of age for subchondral bone HP in OA subjects regardless of DM status.
All other potential models based on findings presented in Table 2 found no significant independent biomarker variables (data not shown). However, some models were underpowered, indicating a lower likelihood of detecting a difference when one actually existed; thus, a lack of significance should be interpreted cautiously.

\section{DISCUSSION}

This pilot study examined diabetes, obesity, and cartilage/bone metabolism variables and uncovered interac- 
(a)

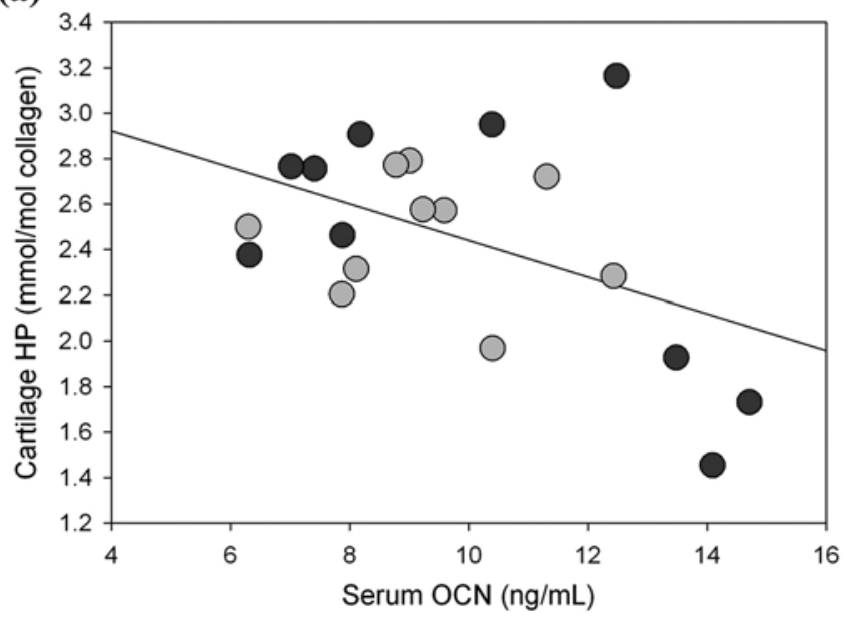

(b)

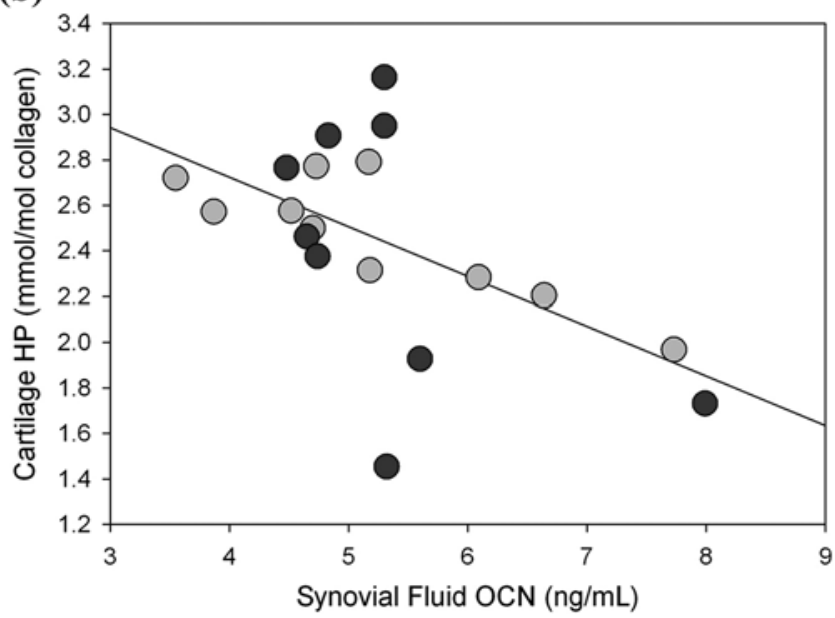

Figure 3.

Correlations between osteocalcin (OCN) and cartilage hydroxylysylpyridinoline (HP). (a) OCN levels in serum were correlated to cartilage HP. (b) OCN levels in synovial fluid were correlated to cartilage HP. Black filled circles represent diabetes mellitus (DM) group, and light gray filled circles represent non-DM group. Regression line is indicated with black line.

tions relevant to bone and joint health that are different in an OA population based on DM status, as well as interactions that are similar in an OA population regardless of DM diagnosis.

The main difference between the DM and non-DM groups is the level of the AGE, pentosidine, in joint tissues. This difference is not surprising, considering high levels of AGEs have been demonstrated in other tissues of DM subjects and animal models of DM [35-37]. Higher levels of other AGEs would be a problem in OA because they lead to increased inflammation due to signaling via the receptor for AGE (RAGE) [38]. Although pentosidine is not itself a ligand for RAGE, when pentosidine is increased in cartilage or bone, tissue brittleness increases and tissue function decreases $[13,16]$. That DM OA subjects differ from non-DM OA subjects in regard to pentosidine is further supported by Model 1, in which the level of OCN in the synovial fluid of the OA knee is inversely correlated to pentosidine levels in the cartilage of the same knee (after adjusting for age and BMI), but only in DM subjects.

OCN is produced by mature osteoblasts and osteocytes as well as by chondrocytes in OA cartilage and is considered a biomarker for bone formation [22,39-40]. A recent perspective article from Clemens and Karsenty presents the hypothesis that higher OCN is associated with improved glucose metabolism, including both increased insulin secretion from the pancreas and increased insulin sensitivity in the peripheral tissues, and that leptin plays a role as a negative regulator of this mechanism [41]. In several human studies of the effect of DM on osteoporosis, a disease of pathological bone metabolism, serum OCN is negatively correlated to HbA1c and other indicators of glucose metabolism [4245]. Our study also finds this inverse correlation between serum OCN and HbA1c. However, multiple regression analysis (adjusting for age and BMI) finds no relationship, though one should note that this model was underpowered.

Interestingly, a different collagen crosslink, HP, is also inversely correlated to synovial fluid OCN. HP is considered a "mature" crosslink since it forms an estimated 7 to 30 days after collagen synthesis [46]. However, this relationship (Model 2) applies regardless of DM status and may represent HP loss with increasing OCN in OA. Although decreased HP is undesired, this effect ( $\beta$ coefficient of Model 2) is much lower than the OCN effect for pentosidine ( $\beta$ coefficient of Model 1). Bone HP appears to be influenced by synovial fluid leptin (Model 3). This model should be interpreted cautiously. BMI is highly correlated to leptin, and age was a "near" significant factor in this slightly underpowered model. However, the $\beta$ coefficient for age is extremely low compared with leptin; thus, even if significant, age would have a very low impact on bone HP. If HP concentration is normalized to total collagen concentration (as is standard for HPLC measurement 
(a)

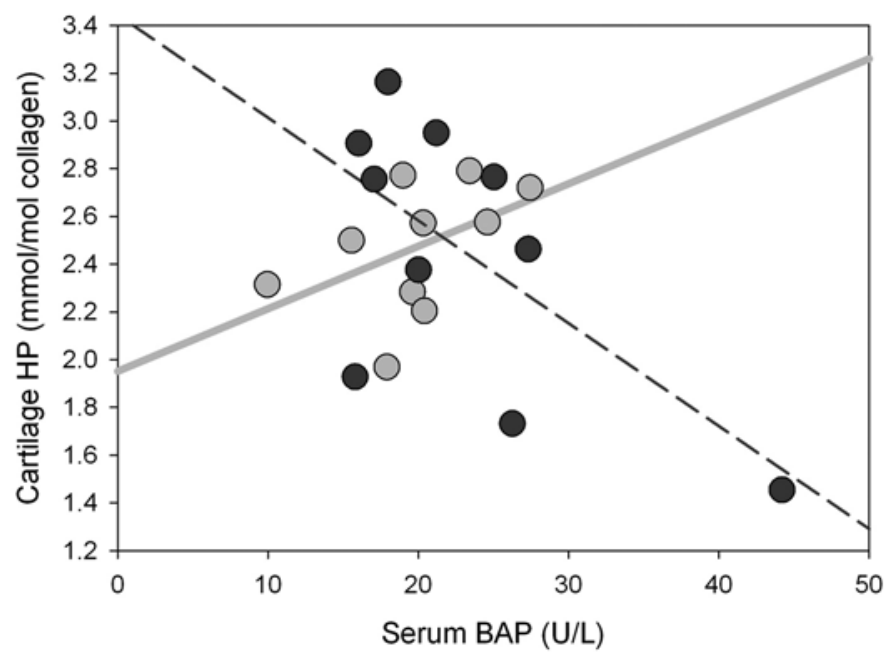

(c)

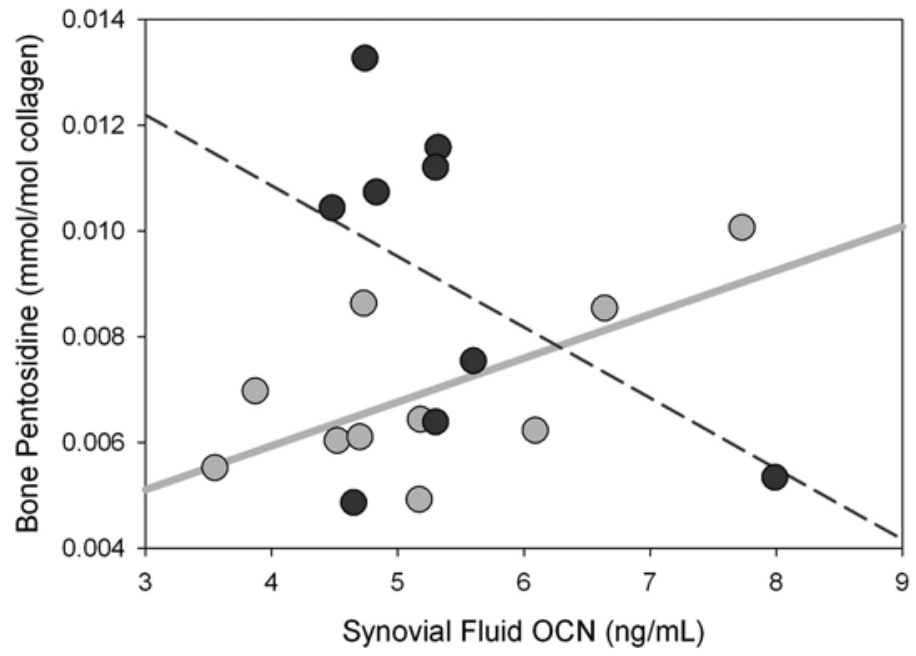

(b)

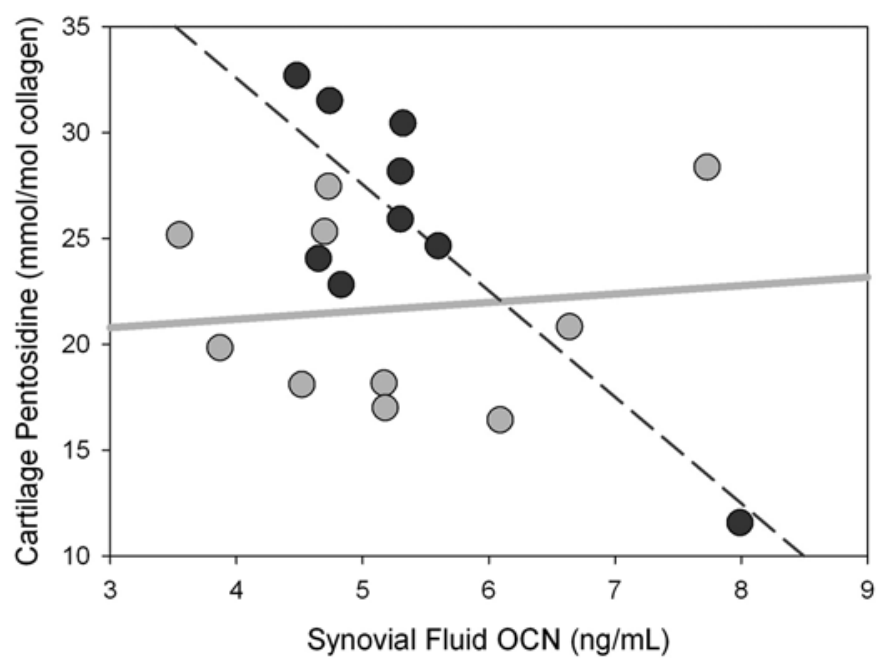

Figure 4.

Correlations between biomarkers and collagen crosslinks that differed between diabetes mellitus (DM) and non-DM groups. (a) Bone alkaline phosphatase (BAP) levels in serum were positively correlated to cartilage hydroxylysylpyridinoline (HP) in non-DM group, but negative in DM group. (b) Osteocalcin (OCN) levels in synovial fluid were not correlated to cartilage pentosidine in non-DM group, but were negatively correlated to cartilage pentosidine in DM group. (c) OCN levels in synovial fluid were not correlated to bone pentosidine in non-DM group, but were negatively correlated to bone pentosidine in DM group. Black filled circles represent DM group, and light gray filled circles represent nonDM group. Regression lines are indicated with dashed black line for DM group and solid gray line for non-DM group.

of HP), then periods of higher collagen turnover, as seen in OA, may decrease overall HP concentration. All subjects of this study experienced late OA in the indexed knee; thus, the inverse relationship between the bone biomarker OCN and cartilage HP seems plausible. However, unlike in cartilage, this relationship was not statistically significant for bone HP. This lack of sensitivity is primarily due to the very low amounts of HP in bone compared with cartilage (data not shown, first reported by Eyre et al. [32]).

Overall, our data are consistent with the hypothesis that higher OCN is correlated to better health, even in peripheral tissues. Other indirect support comes from a study by Berry et al., in which OCN is negatively correlated to OA cartilage loss as measured by magnetic resonance imaging [47]. In this and other studies, however, 
(a)

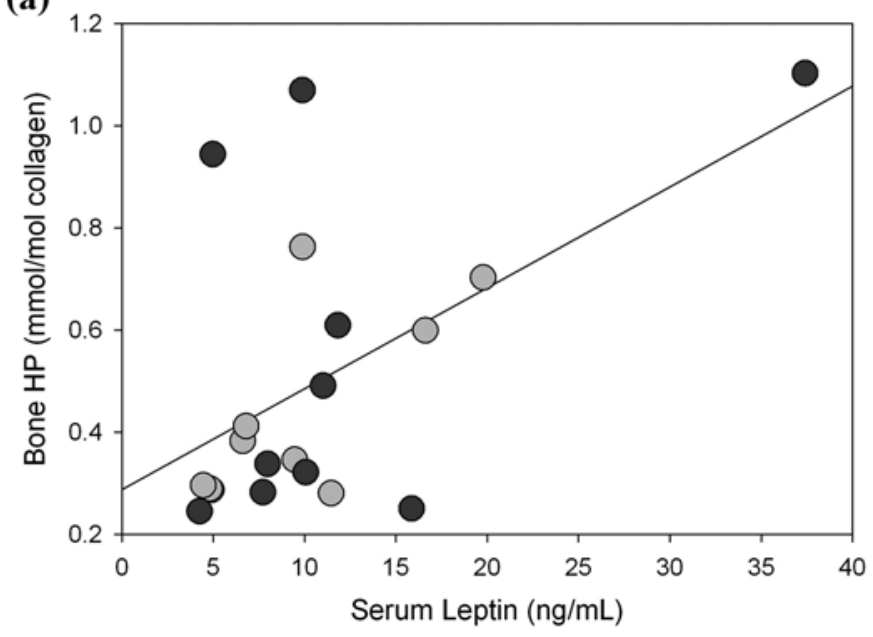

(b)

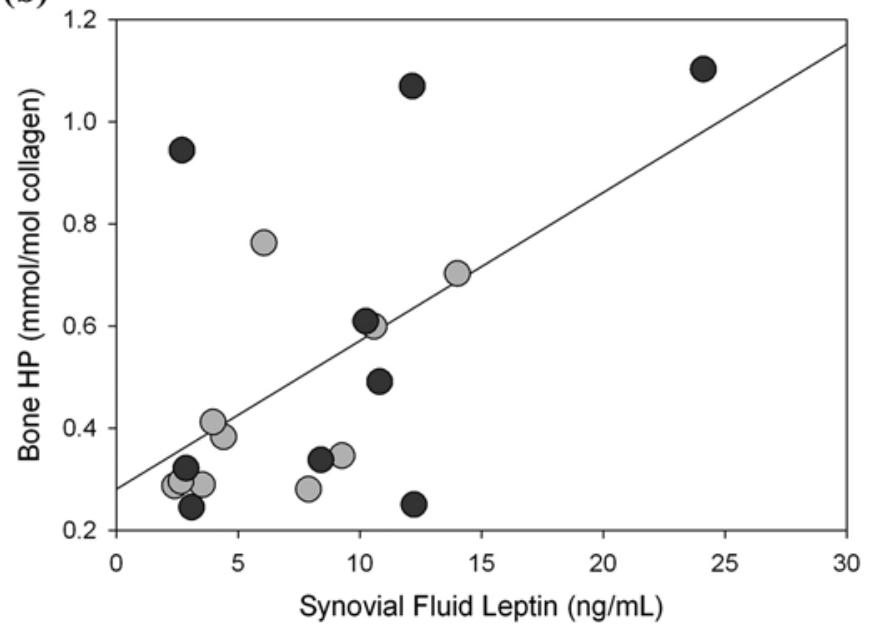

Figure 5.

Correlations between leptin and bone hydroxylysylpyridinoline (HP). (a) Leptin levels in serum were correlated to bone HP. (b) Leptin levels in synovial fluid were correlated to bone HP. Black filled circles represent diabetes mellitus (DM) group, and light gray filled circles represent nonDM group. Regression line is indicated with black line.

DM subjects may or may not have been excluded, but their numbers in the study population and the effect of DM status on outcome measures have not been reported
[47-52]. This may explain why little consensus exists as to whether OCN is positively, negatively, or not correlated to OA presence or severity. To our knowledge, ours is the

Table 3.

Multiple linear regression models for collagen crosslinks. These tests were used to verify association between single independent or explanatory variable (OCN, leptin) and response or dependent variable (pentosidine, HP), when controlling for other explanatory variables (age, BMI).

\begin{tabular}{lcccc}
\hline \multicolumn{1}{c}{ Dependent Variable } & Independent Variables & Coefficient $(\beta)$ & Standard Error & $\boldsymbol{p}$-Value \\
\hline Model 1: $n=9$ DM & Age & 0.122 & 0.217 & 0.60 \\
Cartilage Pentosidine & BMI & -0.522 & 0.290 & 0.13 \\
& OCN (synovial fluid) & -4.750 & 1.090 & 0.007 \\
Model 2: $n=19$ non-DM and DM & Age & 0.00395 & 0.0143 & 0.79 \\
Cartilage HP & BMI & 0.0153 & 0.0258 & 0.56 \\
& OCN (synovial fluid) & -0.232 & 0.0989 & 0.03 \\
Model 3: $n$ = 19 non-DM and DM & Age & -0.00972 & 0.00538 & 0.09 \\
log Bone HP & log Leptin (synovial fluid) & 0.315 & 0.147 & 0.048
\end{tabular}

Note: Pentosidine and HP were measured by high-performance liquid chromatography. Age and BMI values were taken from patient medical records. Synovial fluid OCN, BAP, and leptin were measured by enzyme-linked immunosorbent assay.

These data were tested for normality (Shapiro-Wilk) and for constant variance.

For model 1, adjusted $R^{2}=0.742$, power of performed test with $\alpha=0.050$ : 0.969.

For model 2, adjusted $R^{2}=0.203$, power of performed test with $\alpha=0.050: 0.755$.

For model 3, adjusted $R^{2}=0.279$, power of performed test with $\alpha=0.050$ : 0.790.

$\mathrm{BMI}=$ body mass index, $\mathrm{DM}=$ diabetes mellitus, $\mathrm{HP}=$ hydroxylysylpyridinium, $\mathrm{OCN}=$ osteocalcin .

first study to specifically examine and propose effects of $\mathrm{DM}$ on cartilage pentosidine involving OCN. We propose that OCN is correlated to improved molecular function in
DM joint tissues but that the exact mechanisms are not fully clear at this time.

In the OCN-glucose metabolism hypothesis [41], leptin is proposed as a negative factor. In bone formation, 
as leptin increases, OCN production (tied to osteoblast function) decreases. Leptin metabolism, coincidentally, is also cautiously proposed by others as affecting OA [53]. High leptin levels as found in obesity are proposed to have hormonal effects in the development and/or progression of OA [54-55]. In our study, Model 3 shows local (i.e., synovial fluid) levels of leptin to be a significant factor in subchondral bone HP levels, with age as a potential minor but nonsignificant factor. This suggests that leptin is a positive factor for bone collagen function regardless of DM status, although these data cannot determine a cause-and-effect relationship, particularly since BMI did not significantly differ between groups. Leptin effects on human bone have shown both an osteogenic role and an antiosteogenic role [56-59]. Nonetheless, the majority of these studies have been performed only in women and further study needs to be done to understand fully the relationship between leptin and bone and cartilage. In agreement with other studies [60-61], we find no relationship between these biomarkers in either fluid (data not shown).

The goal of this study was to examine the effect of DM on cartilage and bone metabolism in order to form hypotheses regarding DM-OA and regarding arthroplasty outcomes for those with DM. Patients with comorbid DM appear to receive total joint replacement at a higher rate than non-DM patients, and DM patients aged 46 to 55 have arthroplasty and revision arthroplasty at nearly double the rate of nonDM patients [62]. Our study demonstrates the biomarker for AGEs, pentosidine, is expressed in higher levels in the bone and cartilage of DM patients. The way in which AGEs affect bone and joint metabolism is not entirely clear. We propose that in DM-OA cartilage, AGEs increase inflammation, leading to greater and/or faster tissue degeneration, while greater pentosidine crosslinking leads to brittle articular cartilage that poorly absorbs physiological loading. Since AGEs may decrease osteoblast function of bone formation [63-67], we further propose that following arthroplasty, DM-OA bone is less capable of the bone remodeling and bone formation required for osseointegration of the prosthesis. Two mechanisms that would hinder osseointegration are (1) excessive pentosidine crosslinking that would inhibit collagen degradation needed for remodeling [68-69], and (2) hyperglycemia-mediated decrease in osteoblast cell differentiation and function [66,70]. Impair- ment of these processes could ultimately lead to aseptic loosening requiring revision surgery.

There are limitations to our study. We have only examined patients enrolled for surgery to treat severe OA pain and disability. This study has examined the joint tissues from a specific population set that was similar in race/ ethnicity distribution in the U.S. veteran population, which in the 2001 National Survey of Veterans is reported as 84.8 percent White, 8.8 percent Black or African American, and fewer percentage other races and as 4.5 percent Spanish, Hispanic, or Latino ethnicity [71]. Therefore, our findings can only be directly extrapolated to this specific population. The small sample size decreases the power of this study, and the single sex of this cohort may further limit the generalization of these findings. The DM subjects of this study have largely well-controlled glucose levels (mean HbA1c of 6.6), and the BMI of this group is not significantly different from controls. Larger differences are likely to be seen in the more general population of DM patients, as several studies have identified significant differences in arthroplasty outcomes in DM patients with poorly controlled glucose [2-3,8,72]. Another limitation is that although all blood draws were in the morning, they did not follow subject fasting, which has recently become the standard for clinical studies of biomarkers. The biomarker levels in synovial fluid have been normalized to volume rather than another variable such as total protein; this may have increased variability across subjects. Also, our measurement of biomarkers at a single time point may not accurately reflect ongoing tissue metabolism, which likely had been also influenced by repair processes occurring in late OA.

Finally, we would like to note that, at least anecdotally, the effect of DM status appears more strongly related to one's diagnosis rather than one's present HbA1c level. One DM subject in our study brought his HbA1c down to the normal range before surgery. However, the pentosidine values for both his cartilage and bone are in the range of the DM group, not the non-DM group. Considering the long half-life of fibrillar collagens, including type II (cartilage) and type I (bone), the persistence of glycemic effects on collagen crosslinks is reasonable. An alternative explanation would be the presence of "metabolic memory" as described by Ceriello et al. [73-74]. Metabolic memory suggests that DM complications persist even after glycemic control is regained. This persistence is demonstrated in a DM zebrafish study of bone (fin) regeneration where 2 
weeks or more of streptozotocin-induced hyperglycemia followed by pancreatic regeneration (and return of normoglycemia) still results in impaired bone repair [75]. An analogous metabolic memory effect on human bone repair would have implications for osseointegration following arthroplasty even in those patients who have successfully regained healthy HbA1c levels.

\section{CONCLUSIONS}

Ours is the first study to consider recent hypotheses in the understanding of glucose metabolism as potentially relevant to arthroplasty success in OA patients with diabetes. The present study demonstrates an inverse relationship between the levels of local synovial fluid OCN and the levels of pentosidine/AGEs in OA joint tissues. The implications of these findings are that impaired bone healing in those with diabetes should be further studied at the molecular and tissue levels so that hypotheses regarding potential interventions may be tested. Furthermore, the detrimental effects of pentosidine and other AGEs to bone repair may indicate that control of glycemia before surgery would be beneficial not only to increase perioperative safety but also to avoid impairment of bone remodeling following arthroplasty. Clinicians should be aware that with regard to bone healing, current blood glucose levels may be less important than long-term glycemic control.

\section{ACKNOWLEDGMENTS}

\author{
Author Contributions: \\ Study concept and design: K. B. King, A. Williams, A. Bucknell. \\ Acquisition of data: T. W. Oren, S. Botolin, K. B. King. \\ Analysis and interpretation of data: T. W. Oren, K. B. King. \\ Drafting of manuscript: T. W. Oren, K. B. King. \\ Critical revision of manuscript for important intellectual content: \\ T. W. Oren, S. Botolin, A. Williams, A. Bucknell, K. B. King. \\ Statistical analysis: A. Williams, K. B. King. \\ Administrative, technical, or material support: K. B. King. \\ Study supervision: A. Bucknell, K. B. King. \\ Financial Disclosures: The authors have declared that no competing \\ interests exist. \\ Funding/Support: This material was based on work supported by \\ DePuy Orthopaedics, Inc; University of Colorado Denver Diabetes \\ and Endocrinology Research Center (as part of a Program Grant from \\ the National Institutes of Health/National Institute of Diabetes and \\ Digestive and Kidney Diseases grant P30DK57516); and the Aca- \\ demic Enrichment Fund of the University of Colorado School of Med-
}

icine. Drs. Oren, Williams, and Bucknell receive salary support from the VA. DePuy Orthopaedics, Inc, was not involved in the study design; collection, analysis, and interpretation of data; writing of the report; or decision to submit the report for publication.

Additional Contributions: We thank Mr. Eric Etchill and Ms. Ellen Roper for their technical expertise and assistance. We thank Dr. Rajagopalan for providing sample storage facilities at the VA Medical Center. Dr. Williams is now with the Bay Pines VA Health Care System, Bay Pines, Florida.

Institutional Review: This study was approved by the Colorado Multiple Institutional Research Board at the University of Colorado Denver as well as the Research and Development Committee of the Eastern Colorado Health Care System. All investigations were performed in accordance with the approved protocol to ensure that ethical and humane principles were followed. Written informed consent was obtained from all participants for participation.

Participant Follow-Up: The authors do not plan to inform participants of the publication of this study because contact information is unavailable.

\section{REFERENCES}

1. Lavernia C, Lee DJ, Hernandez VH. The increasing financial burden of knee revision surgery in the United States. Clin Orthop Relat Res. 2006;446:221-26. [PMID: 16672891] http://dx.doi.org/10.1097/01.blo.0000214424.67453.9a

2. Fisher DA, Dierckman B, Watts MR, Davis K. Looks good but feels bad: Factors that contribute to poor results after total knee arthroplasty. J Arthroplasty. 2007;22(6 Suppl 2):39-42. [PMID: 17823013] http://dx.doi.org/10.1016/j.arth.2007.04.011

3. England SP, Stern SH, Insall JN, Windsor RE. Total knee arthroplasty in diabetes mellitus. Clin Orthop Relat Res. 1990;(260):130-34. [PMID: 2225615]

4. Pedersen AB, Mehnert F, Johnsen SP, Sørensen HT. Risk of revision of a total hip replacement in patients with diabetes mellitus: A population-based follow up study. J Bone Joint Surg Br. 2010;92(7):929-34. [PMID: 20595109] http://dx.doi.org/10.1302/0301-620X.92B7.24461

5. Meding JB, Reddleman K, Keating ME, Klay A, Ritter MA, Faris PM, Berend ME. Total knee replacement in patients with diabetes mellitus. Clin Orthop Relat Res. 2003;(416):208-16. [PMID: 14646763] http://dx.doi.org/10.1097/01.blo.0000093002.90435.56

6. Serna F, Mont MA, Krackow KA, Hungerford DS. Total knee arthroplasty in diabetic patients. Comparison to a matched control group. J Arthroplasty. 1994;9(4):375-79.

[PMID: 7964768] http://dx.doi.org/10.1016/0883-5403(94)90047-7

7. Miller DR, Safford MM, Pogach LM. Who has diabetes? Best estimates of diabetes prevalence in the Department of Veterans Affairs based on computerized patient data. Dia- 
betes Care. 2004;27 Suppl 2:B10-21. [PMID: 15113777] http://dx.doi.org/10.2337/diacare.27.suppl 2.B10

8. Yang K, Yeo SJ, Lee BP, Lo NN. Total knee arthroplasty in diabetic patients: A study of 109 consecutive cases. J Arthroplasty. 2001;16(1):102-6. [PMID: 11172278$]$ http://dx.doi.org/10.1054/arth.2001.19159

9. Papagelopoulos PJ, Idusuyi OB, Wallrichs SL, Morrey BF. Long term outcome and survivorship analysis of primary total knee arthroplasty in patients with diabetes mellitus. Clin Orthop Relat Res. 1996;(330):124-32. [PMID: 8804282] http://dx.doi.org/10.1097/00003086-199609000-00015

10. Burner TW, Rosenthal AK. Diabetes and rheumatic diseases. Curr Opin Rheumatol. 2009;21(1):50-54. [PMID: 19077719] http://dx.doi.org/10.1097/BOR.0b013e32831bc0c4

11. Janghorbani M, Van Dam RM, Willett WC, Hu FB. Systematic review of type 1 and type 2 diabetes mellitus and risk of fracture. Am J Epidemiol. 2007;166(5):495-505. [PMID: 17575306$]$ http://dx.doi.org/10.1093/aje/kwm106

12. Therbo M, Petersen MM, Varmarken JE, Olsen CA, Lund B. Influence of pre-operative bone mineral content of the proximal tibia on revision rate after uncemented knee arthroplasty. J Bone Joint Surg Br. 2003;85(7):975-79. [PMID: 14516030] http://dx.doi.org/10.1302/0301-620X.85B7.13882

13. Saito M, Fujii K, Mori Y, Marumo K. Role of collagen enzymatic and glycation induced cross-links as a determinant of bone quality in spontaneously diabetic WBN/Kob rats. Osteoporos Int. 2006;17(10):1514-23. [PMID: 16770520] http://dx.doi.org/10.1007/s00198-006-0155-5

14. Wang X, Shen X, Li X, Agrawal CM. Age-related changes in the collagen network and toughness of bone. Bone. 2002;31(1):1-7. [PMID: 12110404] http://dx.doi.org/10.1016/S8756-3282(01)00697-4

15. Santana RB, Xu L, Chase HB, Amar S, Graves DT, Trackman PC. A role for advanced glycation end products in diminished bone healing in type 1 diabetes. Diabetes. 2003; 52(6):1502-10. [PMID: 12765963$]$ http://dx.doi.org/10.2337/diabetes.52.6.1502

16. Bank RA, Bayliss MT, Lafeber FP, Maroudas A, Tekoppele JM. Ageing and zonal variation in post-translational modification of collagen in normal human articular cartilage. The age-related increase in non-enzymatic glycation affects biomechanical properties of cartilage. Biochem J. 1998; 330(Pt 1):345-51. [PMID: 9461529]

17. Eyre DR, Paz MA, Gallop PM. Cross-linking in collagen and elastin. Annu Rev Biochem. 1984;53:717-48.

[PMID: 6148038] http://dx.doi.org/10.1146/annurev.bi.53.070184.003441

18. Banse X, Sims TJ, Bailey AJ. Mechanical properties of adult vertebral cancellous bone: Correlation with collagen intermolecular cross-links. J Bone Miner Res. 2002;17(9):
1621-28. [PMID: 12211432]

http://dx.doi.org/10.1359/jbmr.2002.17.9.1621

19. Eyre DR. Collagens and cartilage matrix homeostasis. Clin Orthop Relat Res. 2004;(427 Suppl):S118-22.

[PMID: 15480053]

http://dx.doi.org/10.1097/01.blo.0000144855.48640.b9

20. Achemlal L, Tellal S, Rkiouak F, Nouijai A, Bezza A, Derouiche el M, Ghafir D, El Maghraoui A. Bone metabolism in male patients with type 2 diabetes. Clin Rheumatol. 2005;24(5):493-96. [PMID: 15747054] http://dx.doi.org/10.1007/s10067-004-1070-9

21. Thrailkill KM, Liu L, Wahl EC, Bunn RC, Perrien DS, Cockrell GE, Skinner RA, Hogue WR, Carver AA, Fowlkes JL, Aronson J, Lumpkin CK Jr. Bone formation is impaired in a model of type 1 diabetes. Diabetes. 2005;54(10):2875-81. [PMID: 16186388] http://dx.doi.org/10.2337/diabetes.54.10.2875

22. Price PA, Williamson MK, Lothringer JW. Origin of the vitamin K-dependent bone protein found in plasma and its clearance by kidney and bone. J Biol Chem. 1981;256(24): 12760-66. [PMID: 6975778]

23. Pietschmann P, Schernthaner G, Woloszczuk W. Serum osteocalcin levels in diabetes mellitus: Analysis of the type of diabetes and microvascular complications. Diabetologia. 1988;31(12):892-95. [PMID: 3266486]

http://dx.doi.org/10.1007/BF00265373

24. Li MG, Thorsen K, Nilsson KG. Increased bone turnover as reflected by biochemical markers in patients with potentially unstable fixation of the tibial component. Arch Orthop Trauma Surg. 2004;124(6):404-9. [PMID: 15156331] http://dx.doi.org/10.1007/s00402-004-0695-0

25. Dumond H, Presle N, Terlain B, Mainard D, Loeuille D, Netter P, Pottie P. Evidence for a key role of leptin in osteoarthritis. Arthritis Rheum. 2003;48(11):3118-29.

[PMID: 14613274] http://dx.doi.org/10.1002/art.11303

26. Gandhi R, Takahashi M, Syed K, Davey JR, Mahomed NN. Relationship between body habitus and joint leptin levels in a knee osteoarthritis population. J Orthop Res. 2010; 28(3):329-33. [PMID: 19780190]

27. Simopoulou T, Malizos KN, Iliopoulos D, Stefanou N, Papatheodorou L, Ioannou M, Tsezou A. Differential expression of leptin and leptin's receptor isoform (Ob-Rb) mRNA between advanced and minimally affected osteoarthritic cartilage; Effect on cartilage metabolism. Osteoarthritis Cartilage. 2007;15(8):872-83. [PMID: 17350295] http://dx.doi.org/10.1016/j.joca.2007.01.018

28. Presle N, Pottie P, Dumond H, Guillaume C, Lapicque F, Pallu S, Mainard D, Netter P, Terlain B. Differential distribution of adipokines between serum and synovial fluid in patients with osteoarthritis. Contribution of joint tissues to their articular production. Osteoarthritis Cartilage. 2006;14(7):690-95. 
[PMID: 16527497]

http://dx.doi.org/10.1016/j.joca.2006.01.009

29. Ducy P, Amling M, Takeda S, Priemel M, Schilling AF, Beil FT, Shen J, Vinson C, Rueger JM, Karsenty G. Leptin inhibits bone formation through a hypothalamic relay: A central control of bone mass. Cell. 2000;100(2):197-207. [PMID: 10660043] http://dx.doi.org/10.1016/S0092-8674(00)81558-5

30. Bank RA, Beekman B, Verzijl N, De Roos JA, Sakkee AN, TeKoppele JM. Sensitive fluorimetric quantitation of pyridinium and pentosidine crosslinks in biological samples in a single high-performance liquid chromatographic run. J Chromatogr B Biomed Sci Appl. 1997;703(1-2):37-44. [PMID: 3448060] http://dx.doi.org/10.1016/S0378-4347(97)00391-5

31. Bank RA, Jansen EJ, Beekman B, Te Koppele JM. Amino acid analysis by reverse-phase high-performance liquid chromatography: Improved derivatization and detection conditions with 9-fluorenylmethyl chloroformate. Anal Biochem. 1996;240(2):167-76. [PMID: 8811901] http://dx.doi.org/10.1006/abio.1996.0346

32. Eyre DR, Koob TJ, Van Ness KP. Quantitation of hydroxypyridinium crosslinks in collagen by high-performance liquid chromatography. Anal Biochem. 1984;137(2):380-88.

[PMID: 6731820] http://dx.doi.org/10.1016/0003-2697(84)90101-5

33. Eyre DR, Dickson IR, Van Ness K. Collagen cross-linking in human bone and articular cartilage. Age-related changes in the content of mature hydroxypyridinium residues. Biochem J. 1988;252(2):495-500. [PMID: 3415669]

34. Garnero P, Rousseau JC, Delmas PD. Molecular basis and clinical use of biochemical markers of bone, cartilage, and synovium in joint diseases. Arthritis Rheum. 2000;43(5): 953-68. [PMID: 10817547] http://dx.doi.org/10.1002/15290131(200005)43:5<953::AID-ANR1>3.0.CO;2-Q

35. Paul RG, Bailey AJ. Glycation of collagen: The basis of its central role in the late complications of ageing and diabetes. Int J Biochem Cell Biol. 1996;28(12):1297-1310. [PMID: 9022289] http://dx.doi.org/10.1016/S1357-2725(96)00079-9

36. Owen WF Jr, Hou FF, Stuart RO, Kay J, Boyce J, Chertow GM, Schmidt AM. Beta 2-microglobulin modified with advanced glycation end products modulates collagen synthesis by human fibroblasts. Kidney Int. 1998;53(5):1365-73. [PMID: 9573554] http://dx.doi.org/10.1046/j.1523-1755.1998.00882.x

37. Sell DR, Kleinman NR, Monnier VM. Longitudinal determination of skin collagen glycation and glycoxidation rates predicts early death in C57BL/6NNIA mice. FASEB J. 2000;14(1):145-56. [PMID: 10627289]
38. Yan SF, Ramasamy R, Schmidt AM. Mechanisms of disease: Advanced glycation end-products and their receptor in inflammation and diabetes complications. Nat Clin Pract Endocrinol Metab. 2008;4(5):285-93. [PMID: 18332897] http://dx.doi.org/10.1038/ncpendmet0786

39. Goyal N, Gupta M, Joshi K, Nagi ON. Immunohistochemical analysis of ageing and osteoarthritic articular cartilage. J Mol Histol. 2010;41(4-5):193-97. [PMID: 20623325] http://dx.doi.org/10.1007/s10735-010-9278-2

40. Pullig O, Weseloh G, Ronneberger D, Käkönen S, Swoboda B. Chondrocyte differentiation in human osteoarthritis: Expression of osteocalcin in normal and osteoarthritic cartilage and bone. Calcif Tissue Int. 2000;67(3):230-40. [PMID: 10954778] http://dx.doi.org/10.1007/s002230001108

41. Clemens TL, Karsenty G. The osteoblast: An insulin target cell controlling glucose homeostasis. J Bone Miner Res. 2011;26(4):677-80. [PMID: 21433069] http://dx.doi.org/10.1002/jbmr.321

42. Rosato MT, Schneider SH, Shapses SA. Bone turnover and insulin-like growth factor I levels increase after improved glycemic control in noninsulin-dependent diabetes mellitus. Calcif Tissue Int. 1998;63(2):107-11. [PMID: 9685513] http://dx.doi.org/10.1007/s002239900498

43. Kanazawa I, Yamaguchi T, Yamamoto M, Yamauchi M, Kurioka S, Yano S, Sugimoto T. Serum osteocalcin level is associated with glucose metabolism and atherosclerosis parameters in type 2 diabetes mellitus. J Clin Endocrinol Metab. 2009;94(1):45-49. [PMID: 18984661] http://dx.doi.org/10.1210/jc.2008-1455

44. Hwang YC, Jeong IK, Ahn KJ, Chung HY. The uncarboxylated form of osteocalcin is associated with improved glucose tolerance and enhanced beta-cell function in middleaged male subjects. Diabetes Metab Res Rev. 2009;25(8): 768-72. [PMID: 19877133] http://dx.doi.org/10.1002/dmrr.1045

45. Pittas AG, Harris SS, Eliades M, Stark P, Dawson-Hughes B. Association between serum osteocalcin and markers of metabolic phenotype. J Clin Endocrinol Metab. 2009;94(3): 827-32. [PMID: 19088165] http://dx.doi.org/10.1210/jc.2008-1422

46. Ahsan T, Harwood F, McGowan KB, Amiel D, Sah RL. Kinetics of collagen crosslinking in adult bovine articular cartilage. Osteoarthritis Cartilage. 2005;13(8):709-15. [PMID: 16043034] http://dx.doi.org/10.1016/j.joca.2005.03.005

47. Berry PA, Maciewicz RA, Cicuttini FM, Jones MD, Hellawell CJ, Wluka AE. Markers of bone formation and resorption identify subgroups of patients with clinical knee osteoarthritis who have reduced rates of cartilage loss. J Rheumatol. 2010; 37(6):1252-59. [PMID: 20395641] http://dx.doi.org/10.3899/jrheum.091055 
48. Sharif M, George E, Dieppe PA. Correlation between synovial fluid markers of cartilage and bone turnover and scintigraphic scan abnormalities in osteoarthritis of the knee. Arthritis Rheum. 1995;38(1):78-81. [PMID: 7818576] http://dx.doi.org/10.1002/art.1780380112

49. Salisbury C, Sharif M. Relations between synovial fluid and serum concentrations of osteocalcin and other markers of joint tissue turnover in the knee joint compared with peripheral blood. Ann Rheum Dis. 1997;56(9):558-61.

[PMID: 9370881] http://dx.doi.org/10.1136/ard.56.9.558

50. Sowers M, Lachance L, Jamadar D, Hochberg MC, Hollis B, Crutchfield M, Jannausch ML. The associations of bone mineral density and bone turnover markers with osteoarthritis of the hand and knee in pre- and perimenopausal women. Arthritis Rheum. 1999;42(3):483-89. [PMID: 10088771] http://dx.doi.org/10.1002/15290131(199904)42:3<483::AID-ANR13>3.0.CO;2-O

51. Garnero P, Piperno M, Gineyts E, Christgau S, Delmas PD, Vignon E. Cross sectional evaluation of biochemical markers of bone, cartilage, and synovial tissue metabolism in patients with knee osteoarthritis: Relations with disease activity and joint damage. Ann Rheum Dis. 2001;60(6):619-26.

[PMID: 11350852]

http://dx.doi.org/10.1136/ard.60.6.619

52. Bruyere O, Collette JH, Ethgen O, Rovati LC, Giacovelli G, Henrotin YE, Seidel L, Reginster JY. Biochemical markers of bone and cartilage remodeling in prediction of longterm progression of knee osteoarthritis. J Rheumatol. 2003; 30(5):1043-50. [PMID: 12734904

53. Sowers MR, Karvonen-Gutierrez CA. The evolving role of obesity in knee osteoarthritis. Curr Opin Rheumatol. 2010; 22(5):533-37. [PMID: 20485173] http://dx.doi.org/10.1097/BOR.0b013e32833b4682

54. Sandell LJ. Obesity and osteoarthritis: Is leptin the link? Arthritis Rheum. 2009;60(10):2858-60. [PMID: 19790076] http://dx.doi.org/10.1002/art.24862

55. Griffin TM, Huebner JL, Kraus VB, Guilak F. Extreme obesity due to impaired leptin signaling in mice does not cause knee osteoarthritis. Arthritis Rheum. 2009;60(10): 2935-44. [PMID: 19790050]

http://dx.doi.org/10.1002/art.24854

56. Blum M, Harris SS, Must A, Naumova EN, Phillips SM, Rand WM, Dawson-Hughes B. Leptin, body composition and bone mineral density in premenopausal women. Calcif Tissue Int. 2003;73(1):27-32. [PMID: 14506951]

http://dx.doi.org/10.1007/s00223-002-1019-4

57. Iwamoto I, Douchi T, Kosha S, Murakami M, Fujino T, Nagata Y. Relationships between serum leptin level and regional bone mineral density, bone metabolic markers in healthy women. Acta Obstet Gynecol Scand. 2000;79(12): 1060-64. [PMID: 11130088]
58. Odabai E, Ozata M, Turan M, Bingöl N, Yönem A, Cakir B, Kutlu M, Ozdemir IC. Plasma leptin concentrations in postmenopausal women with osteoporosis. Eur J Endocrinol. 2000;142(2):170-73. [PMID: 10664526

http://dx.doi.org/10.1530/eje.0.1420170

59. Sato M, Takeda N, Sarui H, Takami R, Takami K, Hayashi M, Sasaki A, Kawachi S, Yoshino K, Yasuda K. Association between serum leptin concentrations and bone mineral density, and biochemical markers of bone turnover in adult men. J Clin Endocrinol Metab. 2001;86(11):5273-76.

[PMID: 11701691$]$

http://dx.doi.org/10.1210/jc.86.11.5273

60. Tamura T, Yoneda M, Yamane K, Nakanishi S, Nakashima R, Okubo M, Kohno N. Serum leptin and adiponectin are positively associated with bone mineral density at the distal radius in patients with type 2 diabetes mellitus. Metabolism. 2007;56(5):623-28. [PMID: 17444436] http://dx.doi.org/10.1016/j.metabol.2006.12.008

61. Goulding A, Taylor RW. Plasma leptin values in relation to bone mass and density and to dynamic biochemical markers of bone resorption and formation in postmenopausal women. Calcif Tissue Int. 1998;63(6):456-58.

[PMID: 9817937]

http://dx.doi.org/10.1007/s002239900557

62. King KB, Findley TW, Maney M, Williams AE, Bucknell AL. Diabetics receive joint replacements more frequently and at a younger age. Proceedings of the Orthopaedic Research Society 56th Annual Meeting; 2010 Mar 6-9; New Orleans, LA. Rosemont (IL): Orthopaedic Research Society; 2010.

63. Franke S, Siggelkow H, Wolf G, Hein G. Advanced glycation endproducts influence the mRNA expression of RAGE, RANKL and various osteoblastic genes in human osteoblasts. Arch Physiol Biochem. 2007;113(3):154-61. [PMID: 17922311] http://dx.doi.org/10.1080/13813450701602523

64. Sanguineti R, Storace D, Monacelli F, Federici A, Odetti P. Pentosidine effects on human osteoblasts in vitro. Ann N Y Acad Sci. 2008;1126:166-72. [PMID: 18448811] http://dx.doi.org/10.1196/annals.1433.044

65. Ogawa N, Yamaguchi T, Yano S, Yamauchi M, Yamamoto M, Sugimoto T. The combination of high glucose and advanced glycation end-products (AGEs) inhibits the mineralization of osteoblastic MC3T3-E1 cells through glucose-induced increase in the receptor for AGEs. Horm Metab Res. 2007; 39(12):871-75. [PMID: 17960513] http://dx.doi.org/10.1055/s-2007-991157

66. Katayama Y, Akatsu T, Yamamoto M, Kugai N, Nagata N. Role of nonenzymatic glycosylation of type I collagen in diabetic osteopenia. J Bone Miner Res. 1996;11(7):931-37. [PMID: 8797113] http://dx.doi.org/10.1002/jbmr.5650110709 
67. Yamamoto T, Ozono K, Miyauchi A, Kasayama S, Kojima Y, Shima M, Okada S. Role of advanced glycation end products in adynamic bone disease in patients with diabetic nephropathy. Am J Kidney Dis. 2001;38(4 Suppl 1):S16164.

[PMID: 11576945]

http://dx.doi.org/10.1053/ajkd.2001.27428

68. DeGroot J, Verzijl N, Wenting-Van Wijk MJ, Bank RA, Lafeber FP, Bijlsma JWJ, TeKoppele JM. Age-related decrease in susceptibility of human articular cartilage to matrix metalloproteinase-mediated degradation: The role of advanced glycation end products. Arthritis Rheum. 2001; 44(11):2562-71. [PMID: 11710713] http://dx.doi.org/10.1002/15290131(200111)44:11<2562::AID-ART437>3.0.CO;2-1

69. Valcourt U, Merle B, Gineyts E, Viguet-Carrin S, Delmas PD, Garnero P. Non-enzymatic glycation of bone collagen modifies osteoclastic activity and differentiation. J Biol Chem. 2007;282(8):5691-5703. [PMID: 17142454] http://dx.doi.org/10.1074/jbc.M610536200

70. Botolin S, McCabe LR. Chronic hyperglycemia modulates osteoblast gene expression through osmotic and nonosmotic pathways. J Cell Biochem. 2006;99(2):411-24. [PMID: 16619259] http://dx.doi.org/10.1002/jcb.20842

71. 2001 National Survey of Veterans (NSV). Final report [Internet]. Washington (DC): Department of Veterans Affairs; 2003. Available from: http://www1.va.gov/VETDATA/docs/ SurveysAndStudies/NSV_Final_Report.doc

72. Marchant MH Jr, Viens NA, Cook C, Vail TP, Bolognesi MP. The impact of glycemic control and diabetes mellitus on perioperative outcomes after total joint arthroplasty. J Bone
Joint Surg Am. 2009;91(7):1621-29. [PMID: 19571084

http://dx.doi.org/10.2106/JBJS.H.00116

73. Ceriello A, Ihnat MA, Thorpe JE. Clinical review 2: The "metabolic memory": Is more than just tight glucose control necessary to prevent diabetic complications? J Clin Endocrinol Metab. 2009;94(2):410-15. [PMID: 19066300] http://dx.doi.org/10.1210/jc.2008-1824

74. Ceriello A. Hypothesis: The "metabolic memory", the new challenge of diabetes. Diabetes Res Clin Pract. 2009;86 Suppl 1:S2-6. [PMID: 20115927] http://dx.doi.org/10.1016/S0168-8227(09)70002-6

75. Olsen AS, Sarras MP Jr, Intine RV. Limb regeneration is impaired in an adult zebrafish model of diabetes mellitus. Wound Repair Regen. 2010;18(5):532-42.

[PMID: 20840523]

http://dx.doi.org/10.1111/j.1524-475X.2010.00613.x

Submitted for publication September 17, 2010. Accepted in revised form April 18, 2011.

This article and any supplementary material should be cited as follows:

Oren TW, Botolin S, Williams A, Bucknell A, King KB. Arthroplasty in veterans: Analysis of cartilage, bone, serum, and synovial fluid reveals differences and similarities in osteoarthritis with and without comorbid diabetes. J Rehabil Res Dev. 2011;48(10):1195-1210.

DOI:10.1682/JRRD.2010.09.0186

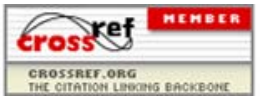

